\title{
Research Paper \\ The Oral Post-Treatment Effect of Hydroethanolic Extract of Origanum vulgare on Acute Kidney Injury Caused by Gentamicin in Rats
}

\author{
${ }^{*}$ Saeed Hajihashemi ${ }^{1} \odot$, Razieh Rajabi ${ }^{1} \odot$ Atefeh Ghiasabadi Farahani $^{1} \odot$ \\ 1. Department of Physiology, School of Medicine, Arak University of Medical Sciences, Arak, Iran.
}

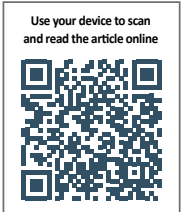

ctration: Hajihashemi S, Rajabi R, Ghiasabadi Farahani A. [The Post-Treatment Effects of Hydroethanolic Extract of Origanum vulgare on Acute Kidney Injury of Gentamicin in Rats (Persian)]. Journal of Arak University of Medical Sciences (JAMS). 2019; 22(5):18-31. https://doi.org/10.32598/JAMS.22.5.18

https://doi.org/10.32598/JAMS.22.5.18

(a) 03

Article Info:

Received: 14 Aug 2019

Accepted: 21 Sep 2019

Available Online: 01 Dec 2019

Key words:

Gentamicin, Neph-

rotoxicity, Origanum

Vulgare, Rat

\section{ABSTRACT}

Background and Aim Gentamicin antibiotic has some side effects such as nephrotoxicity. The aim of this study was to evaluate the post-treatment effects of using hydroethanolic extract of Origanum vulgare (Ov) on nephrotoxicity caused by gentamicin.

Methods \& Materials In this study, 32 male Wistar rats were divided into four groups of control ( $n=8)$, gentami$\operatorname{cin}(n=8 ; 100 \mathrm{mg} / \mathrm{kg} /$ day intraperitoneally for 8 days and gavage of distilled water for 2 days), Ov extract group (intraperitoneal injection of normal saline for 8 days and using $40 \mathrm{mg} / \mathrm{kg}$ Ov extract by gavage for 2 days), and gentamicin+ Ov extract (intraperitoneal injection of gentamicin $100 \mathrm{mg} / \mathrm{kg} /$ day for 8 days and using $40 \mathrm{mg} / \mathrm{kg}$ Ov extract by gavage for 2 days). The concentration of urea, creatinine, sodium, potassium and osmolarity were measured in plasma and urine samples. The right kidney was used to measure Malondialdehyde (MDA) and Ferric Reducing Antioxidant Power (FRAP).

Ethical Considerations This article was obtained from a research proposal approved by the Research Ethics Committee of Arak University of Medical Sciences (Code:IR.ARAKMU.REC. 1394.284)

Results Post-treatment administration of hydroethanolic extract of Ov significantly decreased the concentration of urea, creatinine, absolute sodium excretion, relative sodium and potassium excretion, and MDA levels but significantly increased creatinine, urine osmolality and FRAP levels.

Conclusion Oral administration of Ov extract as post-treatment method improved nephrotoxicity caused by gentamicin use by reducing oxidative stress of oxygen free radicals and lipid peroxidation in the affected kidneys.

\section{Extended Abstract}

\section{Introduction}

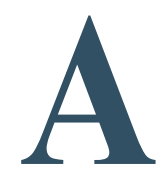

cute Kidney Injury (AKI) is a side effect of aminoglycoside antibiotics, including gentamicin, which is used to treat infections associated with gram-negative bacteria. Gentamicin treatment causes about
$10 \%-15 \%$ of acute renal injury $[1,2]$. Despite the adverse effects of gentamicin such as nephrotoxicity and ototoxicity due to the rapid antibacterial effect and wide spectrum of activity and chemical structure stability and low cost, gentamicin is still being used [3]. The mechanisms of gentamicin induced nephrotoxicity are not completely known.

Previous research showed gentamicin increase the production of Reactive Oxygen Species (ROS) such as super oxide

\section{* Corresponding Author:}

Saeed Hajihashemi, PhD.

Address:Department of Physiology, School of Medicine, Arak University of Medical Sciences, Arak, Iran.

Tel: +98 (861) 34173502

E-mail: hajihashemi@arakmu.ac.ir 
anions. Gentamicin can damage different types of kidney cells such as tubular epithelial cell and glomerular as well as renal artery. In glomeruli, gentamicin can decrease glomerular filtration coefficient (Kf) and decrease glomerular filtration by decrease glomerular mesangial cells.

Previous study has shown the anti-inflammatory and antioxidant effects of flavonoids found in Origanum vulgare. Flavonoids have inhibitory effects on cyclooxygenases or the 5-lipoxygenase pathway in arachidonic acid metabolism. Hydroethanolic Origanum vulgare extract is rich in phenolic antioxidants increasing antioxidant power, reduce oxygen-free radicals known as ROS including superoxide and hydroxyl radicals and peroxides such as hydrogen peroxide $[6,7]$. Previous studies have shown that ROS can cause tissue damage, but flavonoids in the Origanum vulgare extract, such as other plants such as rosemary, rosacanina, etc., have protective effects by reducing ROS in inflammatory processes $[8,9]$.

Nephrotoxicity of gentamicin is induced by producing of free radicals and causing oxidative stress and reducing the power of the antioxidant defense mechanism. Therefore, due to the anti-inflammatory and antioxidant properties of the compounds in the Origanum vulgare extract, we investigated the effects of the Origanum vulgare extract on disorders caused by acute renal injury induced by gentamicin in male rats.

\section{Materials and Methods}

This experimental study was performed on 32 adult Wistar rats. Hydroethanolic extract were obtained from the leaves of Origanum vulgare by rotatory evaporator. Experimental group including:

1. Control group, without receiving gentamicin and Origanum vulgare extract; 2. Gentamicin group, (100 mg/ $\mathrm{kg} /$ day) with intraperitoneally injection of gentamicin for 8 days and $4 \mathrm{ml} / \mathrm{kg}$ distilled water by gavage for two days; 3. Origanum vulgare extract group, intraperitoneally injection of normal saline for 8 days and Origanum vulgare extract (40 mg/kg) by gavage for two days; 4 . Gentamicin and Origanum vulgare extract post treatment group, intraperitoneally injection of gentamicin $(100 \mathrm{mg} / \mathrm{kg} /$ day $)$ for 8 days and Origanum vulgare extract $(40 \mathrm{mg} / \mathrm{kg})$ by gavage for two days.

On the eleven day of the post-treatment protocol the animals were placed in metabolic cages and their urine was collected. The systolic blood pressure was measured from caudal artery using tail cuff of Power Lab device (AD Instruments, Australia). Blood samples were obtained from the abdominal aorta by a cold heparinized syringe. After separation of plasma, the concentration of urea, creatinine, sodium, potassium and osmolarity were measured in plasma and urine samples. Creatinine and Blood Urea Nitrogen (BUN), concentrations of sodium and potassium (K) were measured in plasma and urine samples. Creatinine Clearance $(\mathrm{CCr})$ and absolute and relative sodium and potassium excretion values were also calculated. Both kidneys was separated and left kidneys were fixed in $10 \%$ formalin for histology study. Right kidney was used for MDA (Malondialdehyde) and FRAP (ferric reducing antioxidant power) experiment.

Table 1. The effect of using OV extract on absolute and relative excretion of sodium and potassium, plasma level of creatinine and urea, creatinine clearance and urine osmolality in rats with acute kidney injury caused by gentamicin use

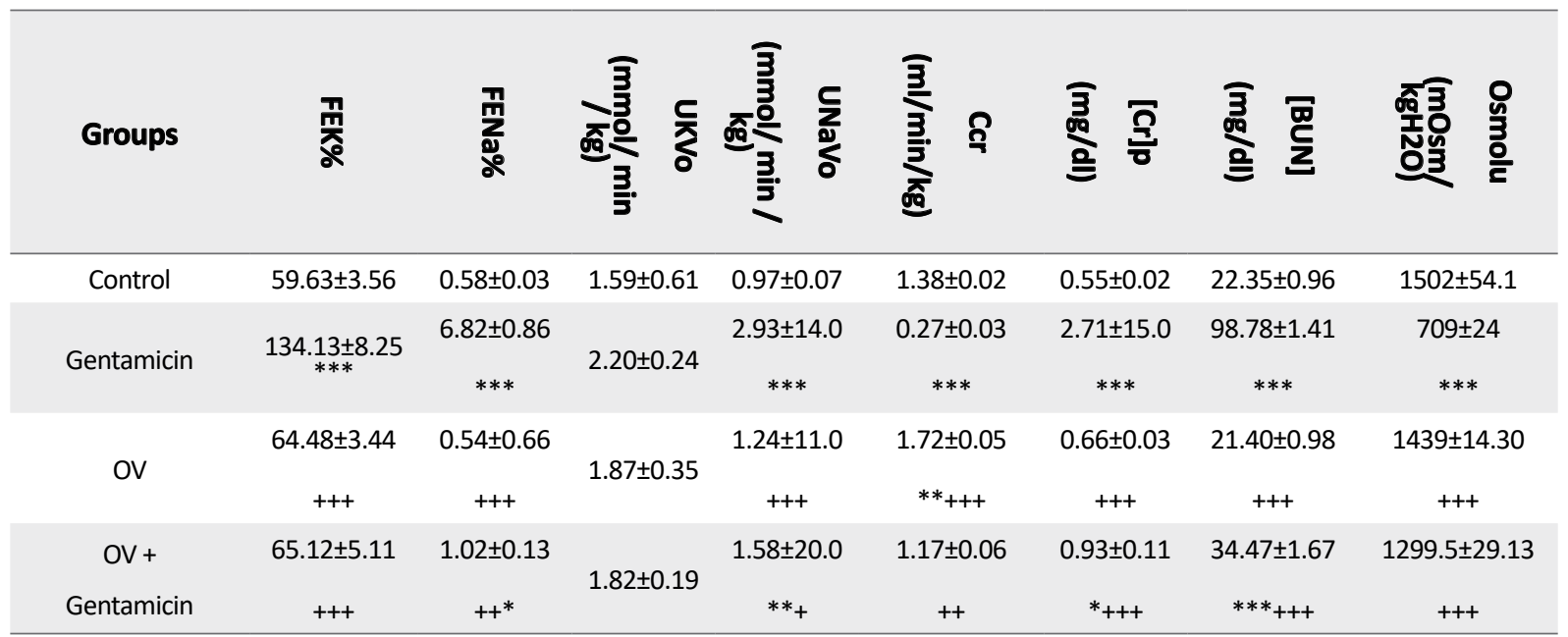



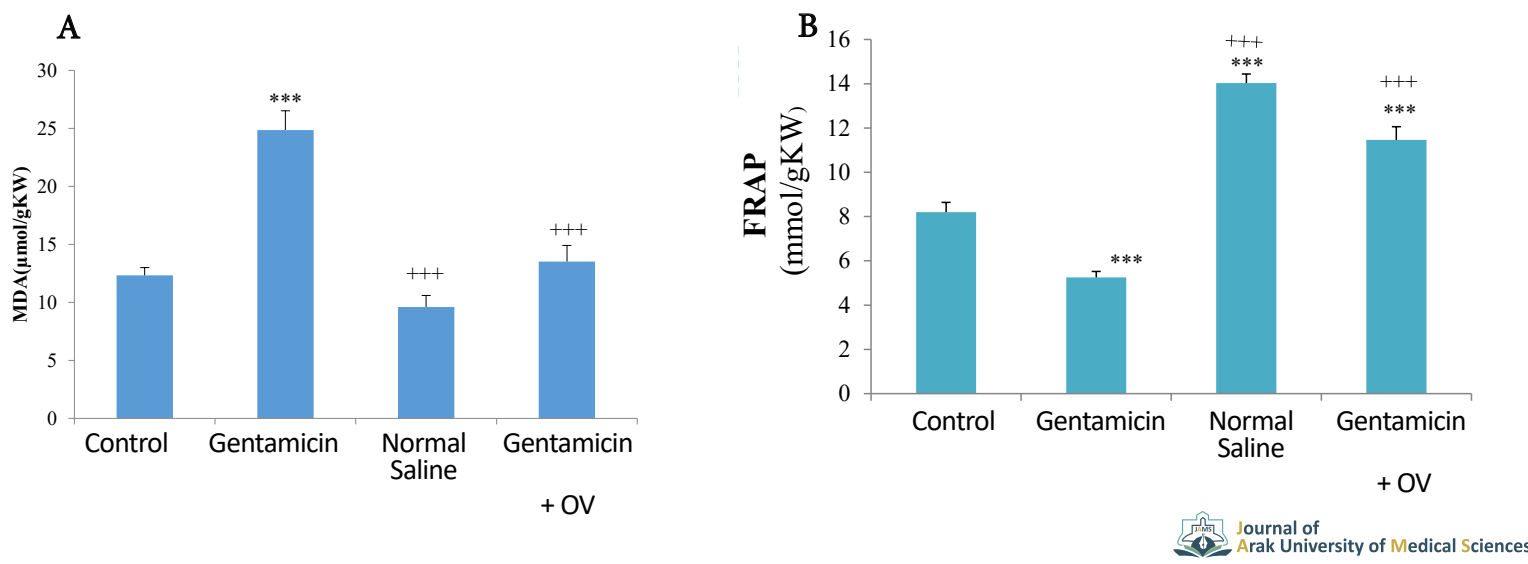

Figure 1. Comparing a. MDA and b. FRAP changes between groups after 8 days of gentamicin administration and 2 days after treatment with OV extract. *** compared to control group $(\mathrm{P}<0.001) ;{ }^{+++}$compared untreated control

\section{Results}

Clearance of creatinine was significantly decreased in the gentamicin group compared to the control group. A significant increase in creatinine clearance was observed in gentamicin-treated rats along with Origanum vulgare extract compared to the gentamicin-treated group.

Relative sodium excretion was significantly decreased in gentamicin-treated rats along with Origanum vulgare extract compared to gentamicin-treated rats. Treated with Origanum vulgare extract was significantly decreased relative potassium excretion in compared to the gentamicin group. In gentamicin-treated rats treated with Origanum vulgare extract the amount of absolute sodium excretion showed a significant decrease in compared to the gentamicin group.

Urinary sodium and potassium excretion were significantly increased in the gentamicin group compared to the control group. There was a significant decrease in urinary sodium and potassium excretion in gentamicintreated rats along with Origanum vulgare ethanol extract compared to gentamicin group. Gentamicin significantly increased urinary creatinine concentration compared to the control group. Gentamicin-treated mice treated with ethanolic Origanum vulgare extract showed a significant decrease in urinary creatinine concentration compared to gentamicin group.

Gentamicin significantly decreased urinary urea excretion compared to the control group. Gentamicin-treated mice treated with ethanolic extract of Origanum vulgare showed a significant increase in urinary urea excretion compared to gentamicin group. Gentamicin-treated rats treated with ethanolic extract of Origanum vulgare showed significantly increased urinary osmolality compared to the gentamicin-treated group.

Gentamicin significantly increased plasma creatinine and blood urea nitrogen concentration compared to the control group. Plasma creatinine and blood urea nitrogen concentration in gentamicin-treated rats along with Origanum vulgare extract significantly decreased compared to gentamicin group (Table 1).

Treatment with Origanum vulgare extract significantly increased FRAP in kidney tissue compared to gentamicin group. In the gentamicin group, MDA level in kidney tissue was significantly increased compared to the control group. After treatment with Origanum vulgare extract, MDA 54\% decreased compared to the gentamicin group (Figure 1). Histology studies showed that gentamicin causes severe damage to the kidney tissue. Microscopic examination showed that the Origanum vulgare extract significantly improved gentamicin induced tissue damage.

\section{Discussion}

The results showed that Origanum vulgare ethanol extract after oral treatment reduces the effects of gentamicin induced nephrotoxicity. The results showed that gentamicin increased plasma creatinine and urea levels, decreased creatinine and urea clearance and consequently decreased urinary excretion. This change indicated impair in the kidney function and induce renal toxicity. These changes in renal function may be due to a decrease in Glomerular Filtration Rate (GFR) and cell necrosis as well as tubular cell loss [17].

Similar to previous studies, gentamicin induced tubular cell necrosis, tubular cell shedding, formation of protein molds in the lumen, vacuolization of the tubular cells, 
decreased red blood cell count in the glomerulus, and increased Bowman capsule space [15]. Origanum vulgare ethanol extract can decrease the amount of tubular cell necrosis, decrease in tubular cells proliferation, formation of protein casts in the lumen, vacuolation of the tubular cells, and decrease of Bowman capsule space on the tissue changes caused by gentamicin.

Gentamicin produces oxidative stress by generating ROS. The balance between antioxidant ability and production of ROS is impaired. ROS resulting from oxidative stress, including superoxide anions and hydroxyl radicals, increases cell damage anddeath [19].

Gentamicin induces glomerular mesangial cells contraction by producing ROS and decreases GFR by decreasing filtration coefficient (Kf) [22]. With the decrease in GFR, creatinine clearance also decreased, which increased the creatinine and urea in the blood. The use of antioxidants by reducing free radicals prevents contraction of mesangial cells and consequently decreases GFR and consequently increases creatinine clearance and decreases plasma urea and creatinine concentration.

\section{Ethical Considerations}

\section{Compliance with ethical guidelines}

This study obtained its ethical approval form the Research Ethics Committee of Arak University of Medical Sciences (Code: 90-106-8). All tests on animals were approved by the ethics committee for laboratory animals of this university.

\section{Funding}

This study extracted from a research proposal approved by the Arak University of Medical Sciences. We received financial support from the Deputy for Research and Technology of this university.

\section{Authors' contributions}

Conceptualization, methodology, validation, and formal analysis: Saeed Hajihashemi; Investigation, resources, analysis and initial draft preparation: Razieh Rajabi and Atefeh Ghiasabadi Farahani.

\section{Conflicts of interest}

The authors declare no conflict of interest

\section{Acknowledgements}

The authors would like to thank the Deputy for Research and Technology of Arak University of Medical Sciences for their support. 



\title{
اثرات يسدرمانى عصارهاتانولى تياه مرزنجوش بر آسيب حاد كليوى ايجادشده توسط جنتامايسين

"سعيد حاجىهاشمى' •، راضيه رجبى' •، عاطفه غياثآبادى فراهانى'

ا.كروه فيزيولورى، دانشكده يزشكى، دانشكاه علوم يزشكى اراك، اراى ، ايران.

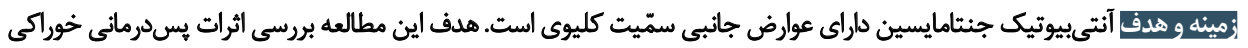

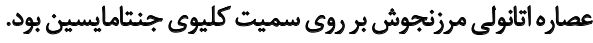

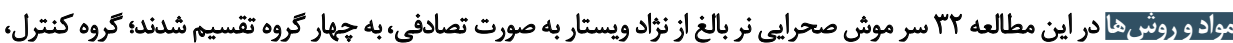

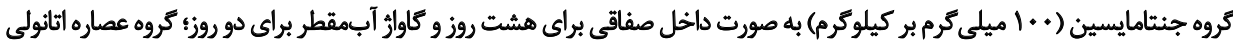

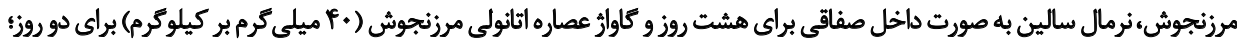

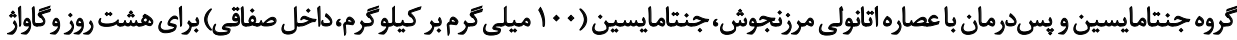

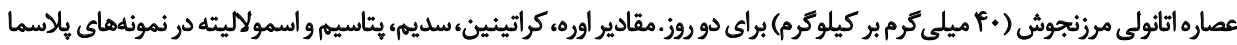

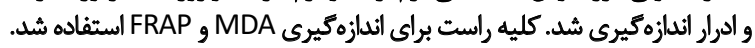

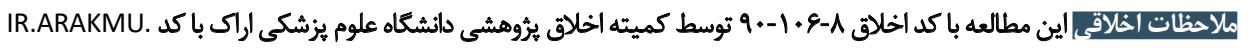
REC. 1394.284

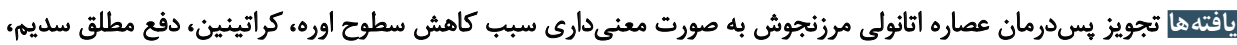

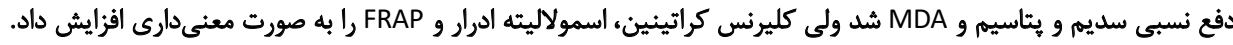

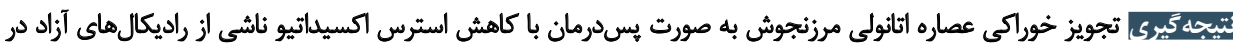

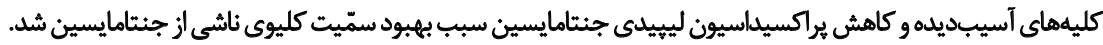

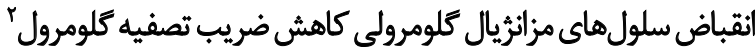
مelat

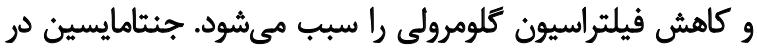

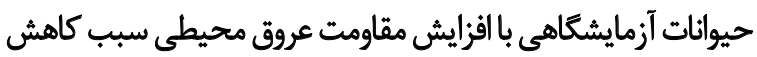

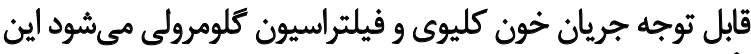

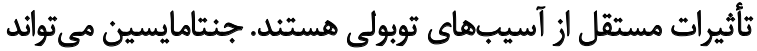

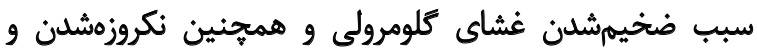

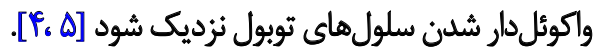

كياه مرزنجوش با نام علمى Origanum vulgare از خانواده

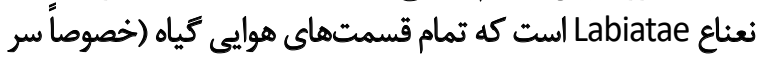

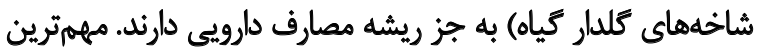

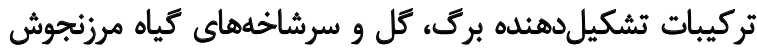

سمّيت كليوى ازعوارض جانبى آنتىبيوتيكهاى آمينوخليكوزيدى،

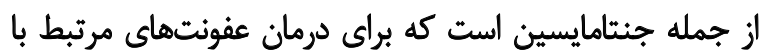

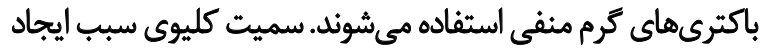

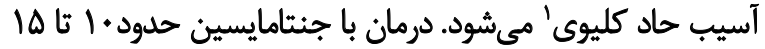

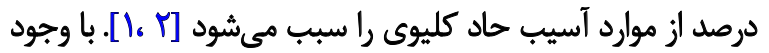

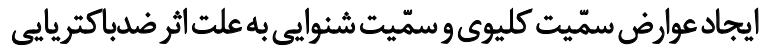
سريع وطيف گسترده فعاليت و يايداري ساختمان شيميائى و هزينه

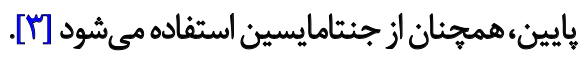
جنتامايسين مى تواندبهانواع مختلف سلولهاي كليه آسيب برساند.

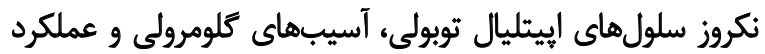

\section{……...}


بركهاي جمع آورىشده در سايه خشك شد و سيس هزار گرم آن با بإيا

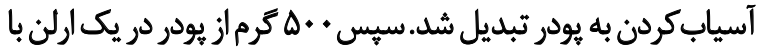

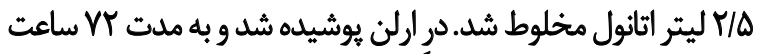

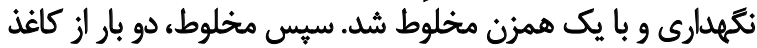

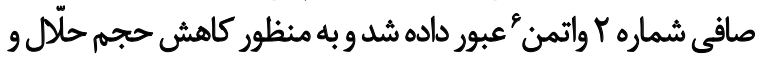

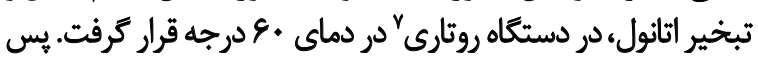

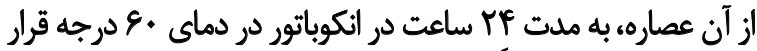

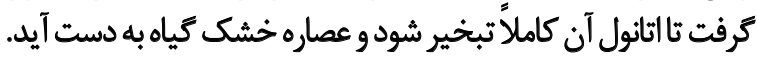

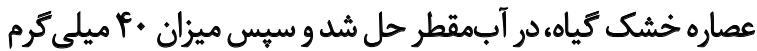

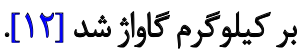

كروهاي مورد مطالعه در اين بثروهش عبارت بودند ازتروه كنترل:

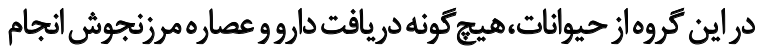

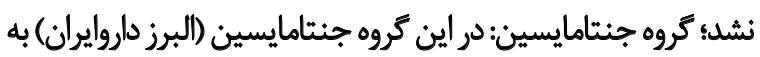

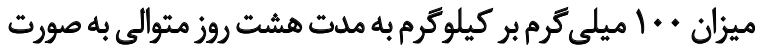

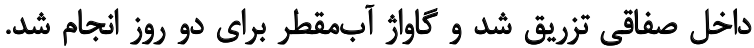

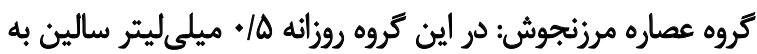

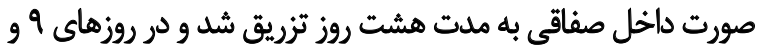

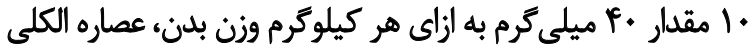

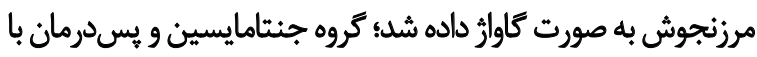

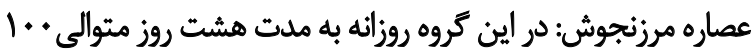

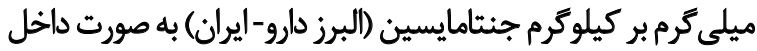

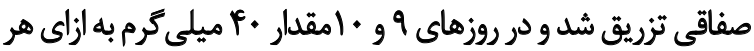

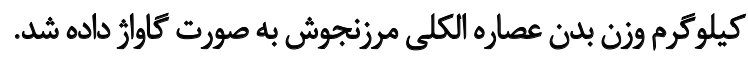

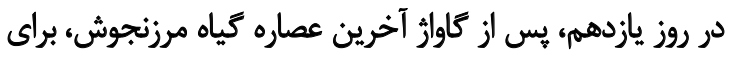

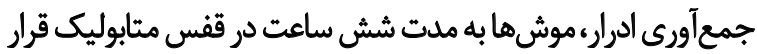

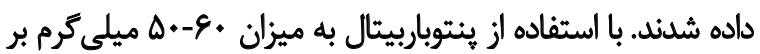

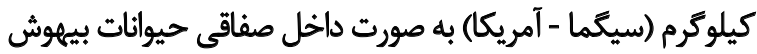

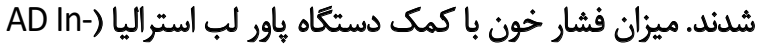

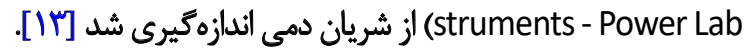
با استفاده از سرنك هيارينه خون كيرى از آئورت شكمي انجام و

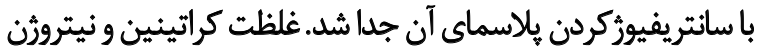

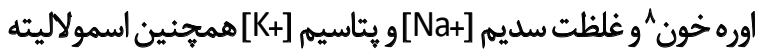

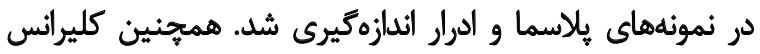

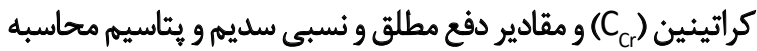

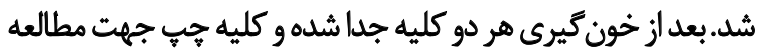

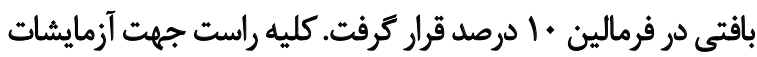

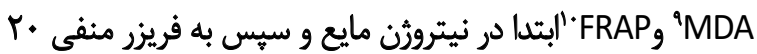

\section{Whatman}

7. Rotatory Evaporator

8. Blood Urea Nitrogen; BUN

9. Malondialdehyde

10. The Ferric Reducing Antioxidant Power (FRAP)
سينالول،سنيئول،تيمول، كارواكرول،ميرسن، كاريوفيلن، تانن،صمغ،

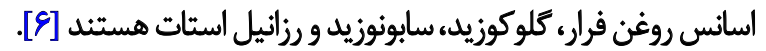
تحقيقات قبلى اثرات ضدالتهابى و آنتىاكسيدانى فلاونوئيدهاى

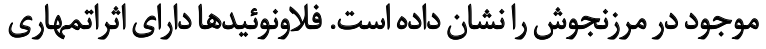

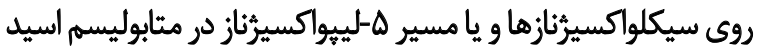

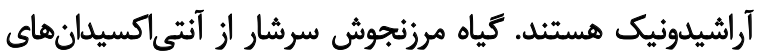

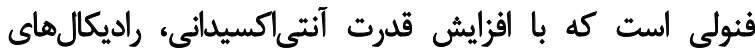

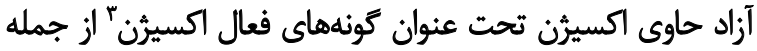

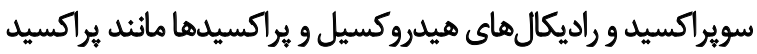

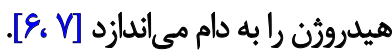

مطالعات كذشته نشان داده است كه ROS مي تواند سبب

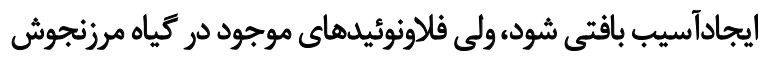

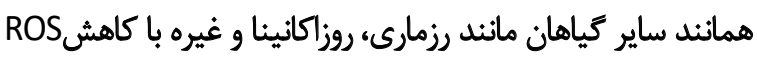

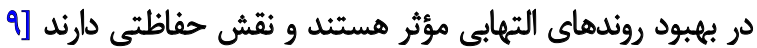

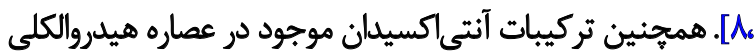

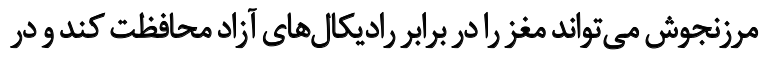

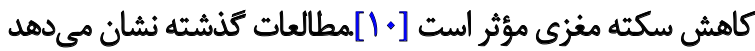

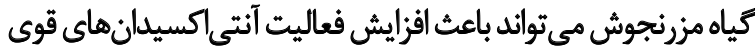

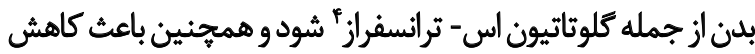

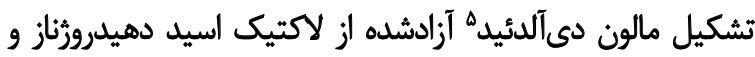
آسيارتات آمينوترانسفراز مىشود [1 [1 ]

با توجه به اينكه مشخص شده است كه جنتامايسين باديا توليدراديكالهاى آزاد، ايجاد استرس الكسيداتيو و كاهش قدئ قدرت

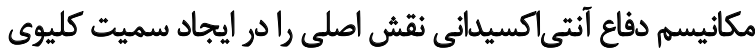

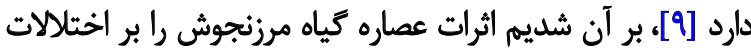

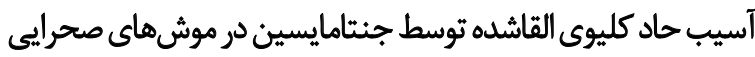

$$
\text { موراد ورابرسى كنيه. }
$$

جهت انجام اين مطالعه تجربى از ب س سر موش صحرايى نر سفيد

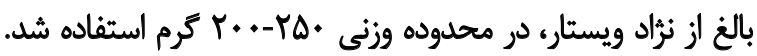

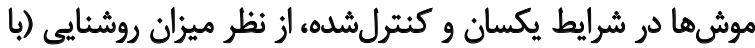

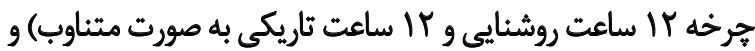

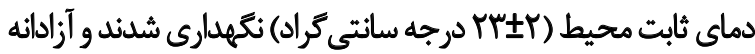
به آب و غذاى كافي دسترسى داشتند.

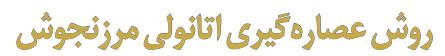

بركهاي كياه مرزنجوش توسط كارشناس هرباريوم كروه

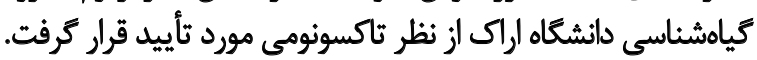

3. Reactive Oxygen Species (ROS)

4. Transferase- GSH Glutathione S-transferases

5. Malondialdehyde 


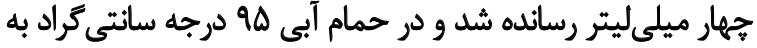

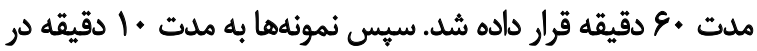

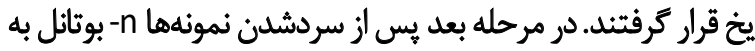

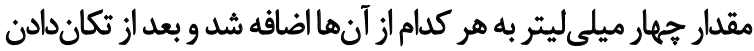

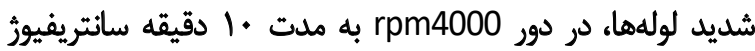

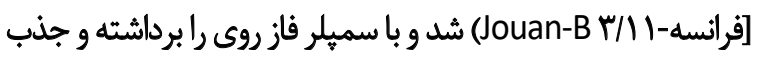

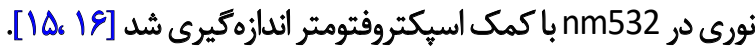

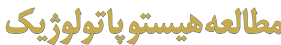

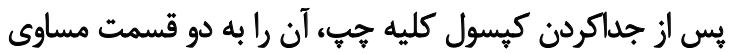

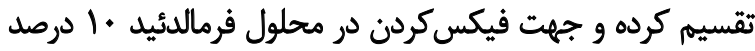

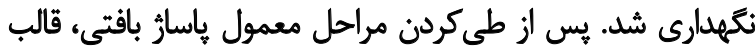

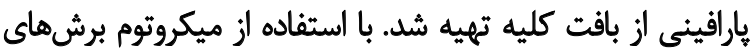

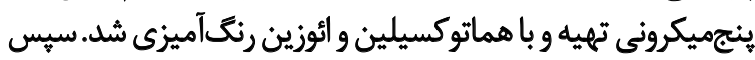
توسط متخصص آسيبشناسى ميزان آسيب بافتي مشئي مشخص

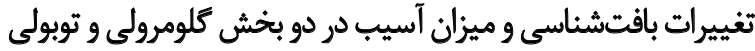

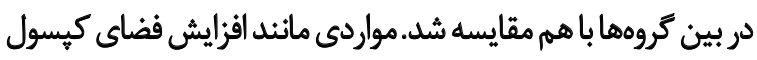

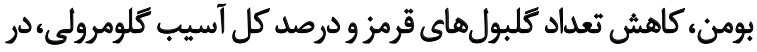

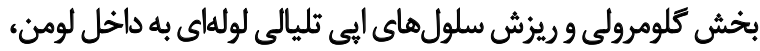

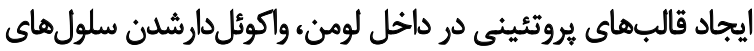

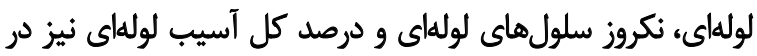

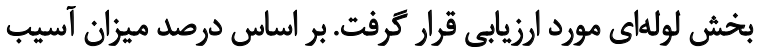

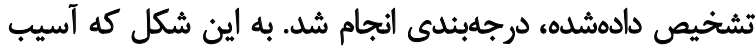

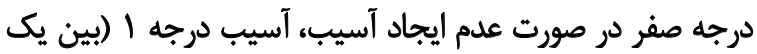

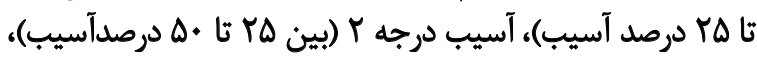

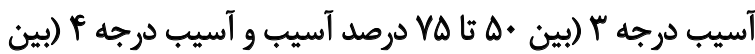

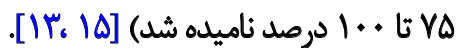

S)

دادهها به صورت ميانكين \pm انحراف معيار نشان داده شد.

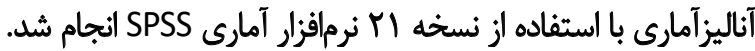

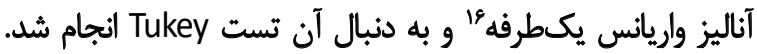

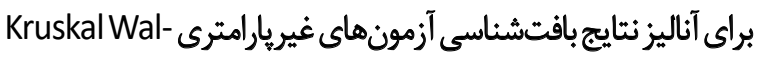

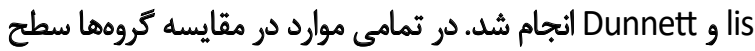

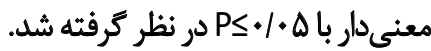

ياقتهها

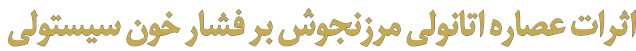

فشار خون سيستولى بين هيجكدام از گروهها تغيير معنى دارى

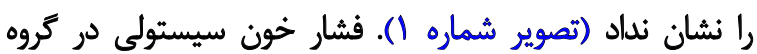

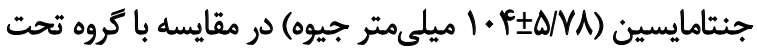

16. ANOVA

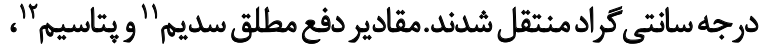

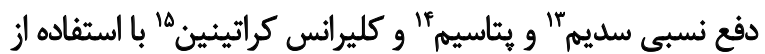

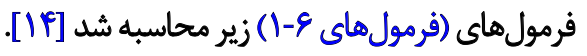

1. $V^{\circ}(\mu l / m i n . g k w)=(1000 \times U F R) /(K W \times 720)$

2. $C_{C r}(\mathrm{ml} / \mathrm{min} . \mathrm{gkw})=\left(\mathrm{V}^{\circ} / 1000 \times \mathrm{UCr}\right) / \mathrm{PCr}$

3. $U_{N a} V(\mu \mathrm{mol} / \mathrm{min} . g k w)=\left(V^{\circ} \times U N a\right) / 1000$

4. $U_{K} V(\mu \mathrm{mol} / \mathrm{min} . g k w)=\left(V_{x}^{\circ} U K\right) / 1000$

5. $F E_{N a}=(U N a \times P C r) /(P N a \times U C r) \times 100$

6. $F E_{K}=(U k \times P C r) /(P k \times U C r) \times 100$

FRAP أزمانش

در اين آزمايش ظرفيت آنتىاكسيدانى نمونهها با استفاده روش

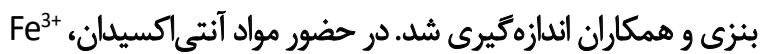

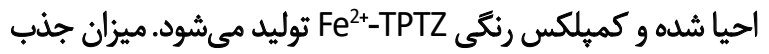

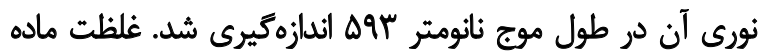

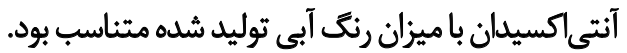

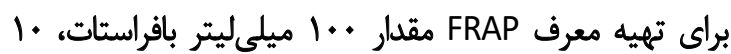

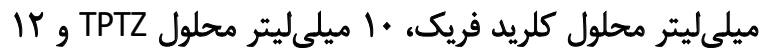

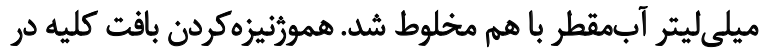

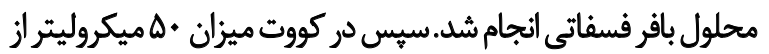

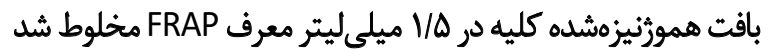

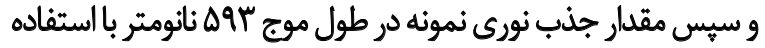

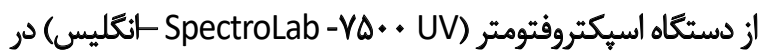

برابر شاهد آن اندازمخيرى شد [IIT)

أزمايش مالرن دي آللدئيد

محصول نهايى يراكسيداسيون ليبيدى در بافتها مالون

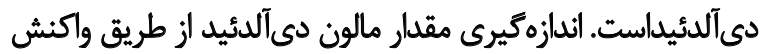

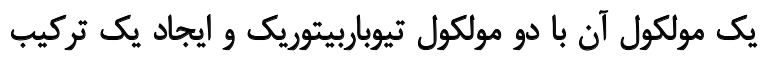

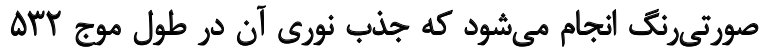

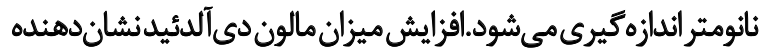
افزايش استرس اكسيداتيو و توليد راديكال هاى آزاد استئ.

براى اندازهيرى مالون دى آلدئيد مقدار . . F ميكروليتر از نمونه

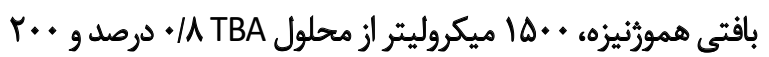

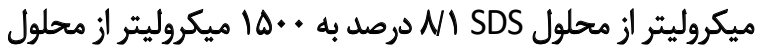

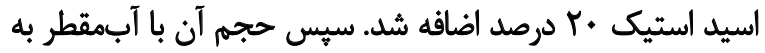

11. Absolute excretion of sodium: $U_{\mathrm{Na}}$ oo

12. Absolute excretion of potassium: $\mathrm{U}_{\mathrm{K}} \mathrm{V}$ o

13. Fractional Excretion of sodium $\left(\mathrm{FE}_{\mathrm{Na}}\right)$

14. Fractional Excretion of potassium $\left(\mathrm{FE}_{\mathrm{K}}\right)$

15. Clearance of Creatinine $\left(\mathrm{C}_{\mathrm{Cr}}\right)$ 
سديم نسبت به كروه جنثّاميسين مشاهده شد (1 + > >P) (جدول

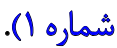

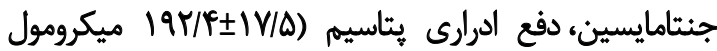

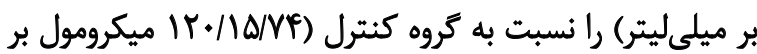

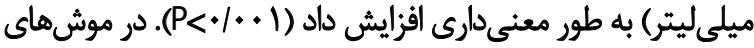

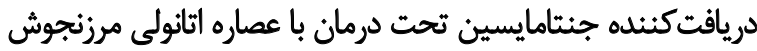

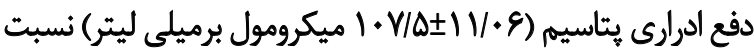

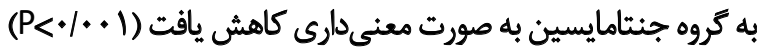
(جدول شماره (). (بنامين

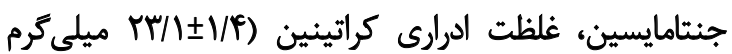

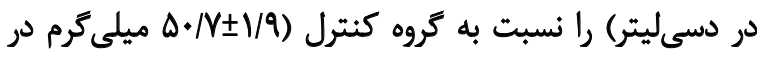

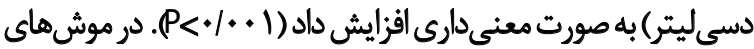

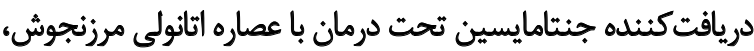

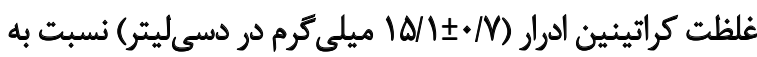

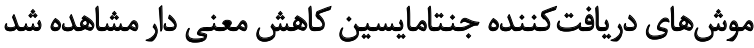

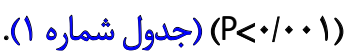

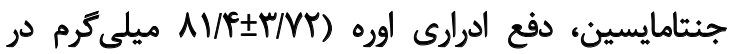

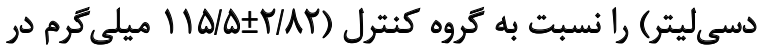

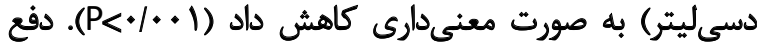

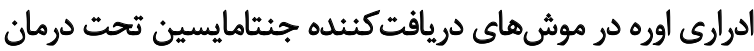

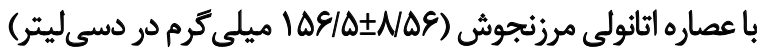

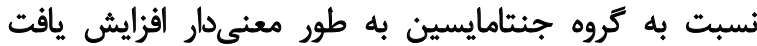

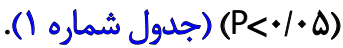

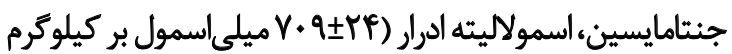

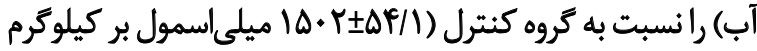

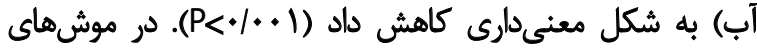

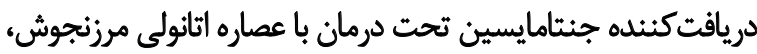

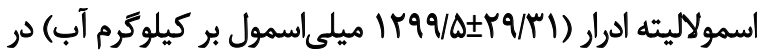
مقايسه باكروه دريافت كننده جنتامايسين به صورت معنى دار افزرايش
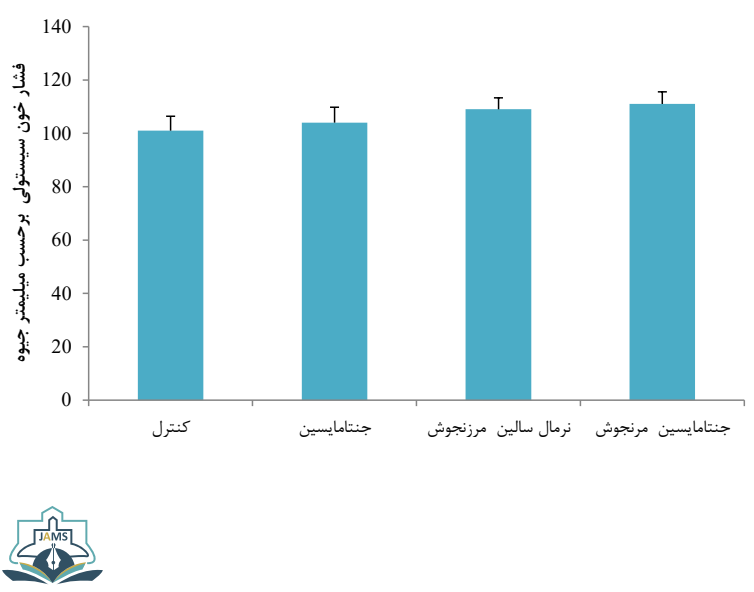

تصوير ا. مقايسه تغييرات فشار خون سيستولى بين كروه ها ناشى از هشت روز تجويز جنتامايسين و دو روز يس درمان با عصاره اتانولى مرزنجوش

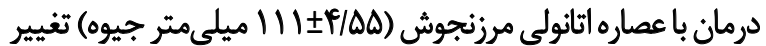

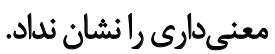

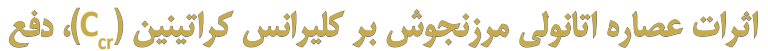

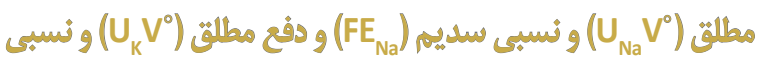
( $\left(F E_{k}\right)$

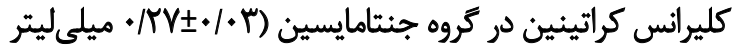

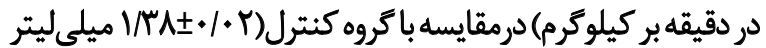

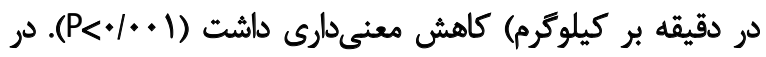

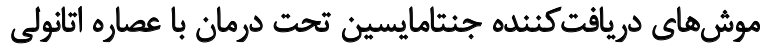

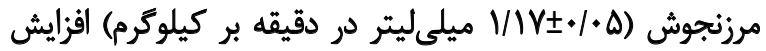

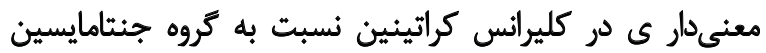

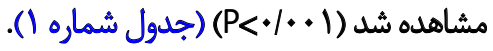

در موشهاى دريافت كننده جنتامايسين، دفع نسبى سديمنسبت

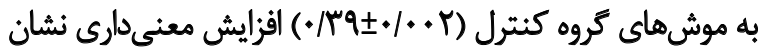

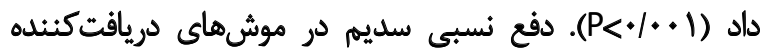

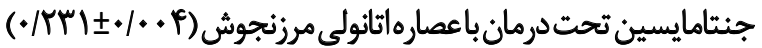

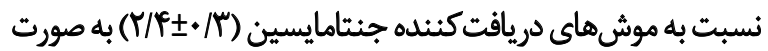

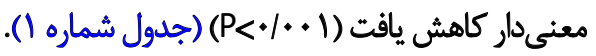
در موشهاى دريافتكنتده جنتامايسين دفع نسبى بتاسيم

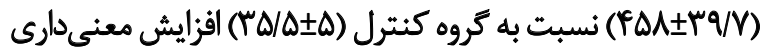

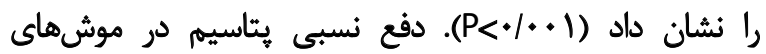

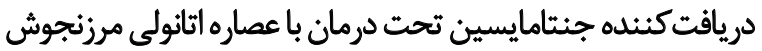

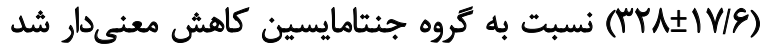

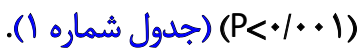

دفع مطلق سديم در موشهاى دريافتكنثده جنتامايسين

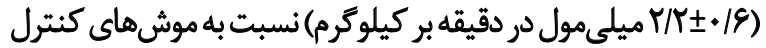

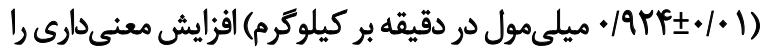

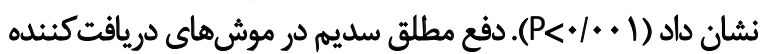

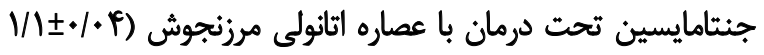

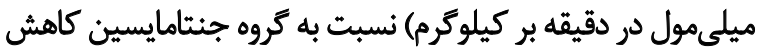

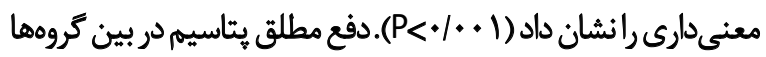
تغيير معنى دارى را نشان نداد (جدول شماره ().

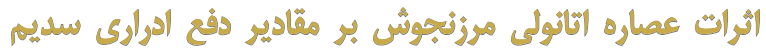

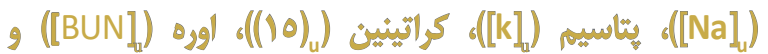
(Osmol) (اسمولاليتئه (Ral)

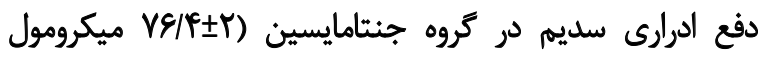

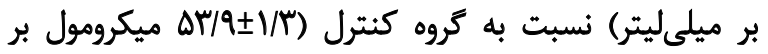

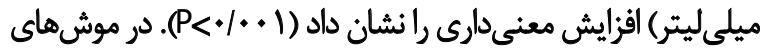

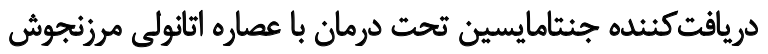

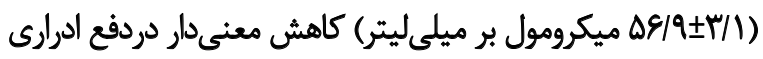




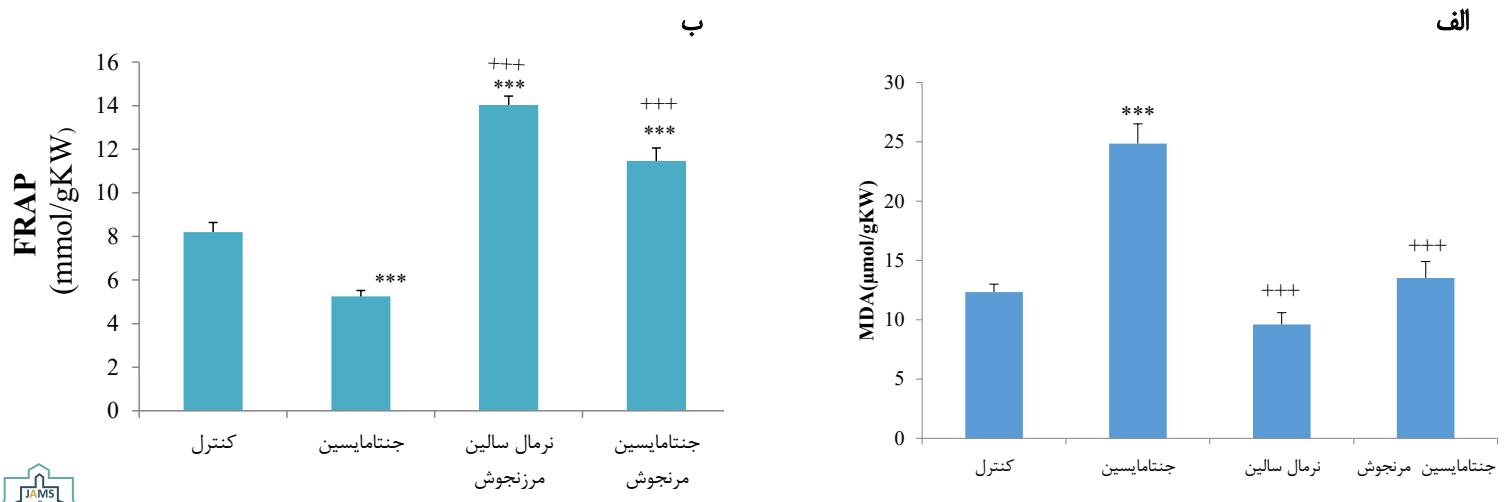

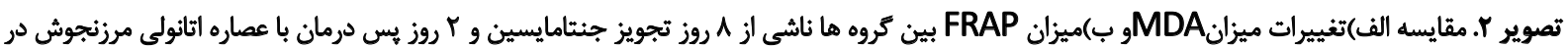
مقايسه با كروه كنترل؛

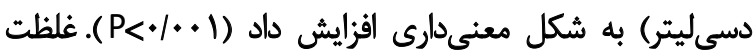

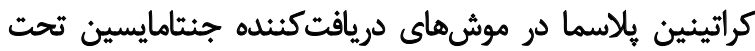

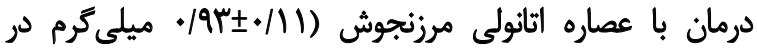

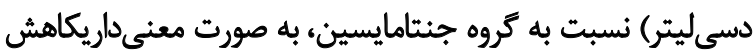

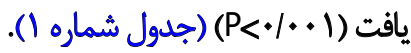

يأفت (1 + + P< (جدول شماره 1).

أ

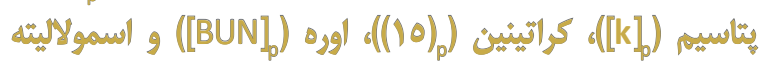

(Osmol)

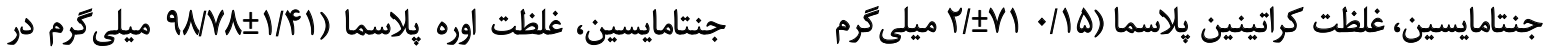

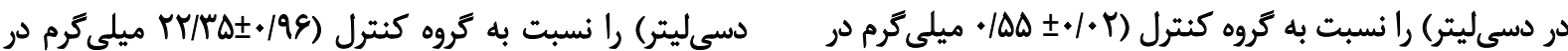

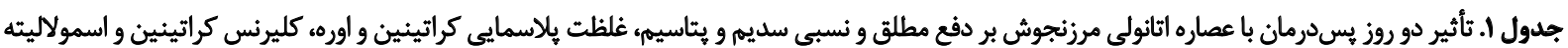

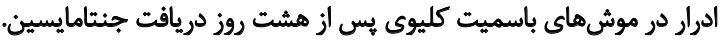

\begin{tabular}{|c|c|c|c|c|c|c|c|c|}
\hline 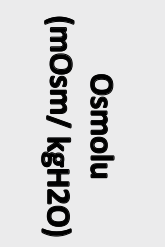 & 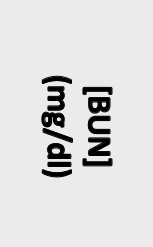 & 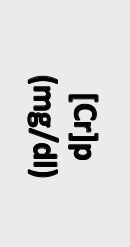 & $\sum_{\substack{0 \\
0}}^{\frac{3}{3}} \Omega$ & 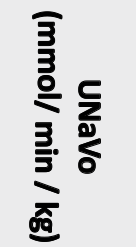 & 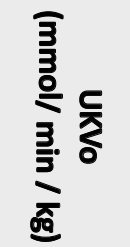 & FENa\% & FEK\% & كاروهها هامها \\
\hline$\Delta \Delta+Y \pm \Delta F / \Lambda$ & $r T / T \Delta \pm+/ Q$ & $+/ \Delta \Delta \pm+1+Y$ & I/rAE+1+r & $\cdot / 9 v \pm \cdot 1 \cdot V$ & $1 / 09 \pm . / 81$ & $\cdot|\Delta A \pm=|+\mu$ & $\Delta Q / F+ \pm T / \Delta F$ & كنترل \\
\hline $\begin{array}{c}r . q \pm m f \\
\cdots\end{array}$ & $\underset{\text { W... }}{\text { Q }}$ & $r M \pm \mid \Delta /$ & 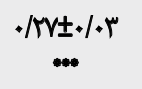 & $\underset{*}{r / a r \pm I f / *}$ & $T / T \cdot \pm \cdot M$ & g/AYI./NE & IMF/IF士NTS & جثتامايسين \\
\hline 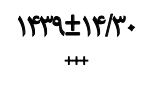 & $\begin{array}{c}M / x+ \pm \cdot / M \\
+\end{array}$ & $\begin{array}{c}.18 E \pm \cdot 1 \cdot r \\
+\end{array}$ & $M \pm \pm .100$ & $\begin{array}{c}1 / M \pm \pm 11 / \\
+\end{array}$ & V/AY士./TQ & 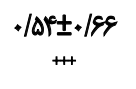 & $\begin{array}{c}e f / p+4 / p e \\
+\end{array}$ & $\begin{array}{c}\text { مرزنجوش } \\
+\end{array}$ \\
\hline 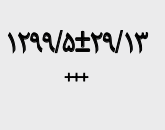 & $M F / F Y \pm 1 / F$ & . $/ 9 \Psi \pm \cdot / 11$ & $\begin{array}{c}1 / 1 V \pm+/ .8 \\
+\end{array}$ & $\begin{array}{c}V / \Delta A \pm r+1 \\
+*\end{array}$ & $1 / 1 Y \pm \cdot / 19$ & $\begin{array}{c}V+r \pm+/ \| r \\
*++\end{array}$ & $9 \Delta / / r \pm \Delta / 11$ & 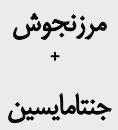 \\
\hline
\end{tabular}

$\mathrm{FE}_{\mathrm{K}}=$ Potassium fraction excretion; $\mathrm{FE}_{\mathrm{Na}}=$ Sodium fraction excretion; $\mathrm{UK}_{\mathrm{V}}^{\circ}=$ Potassium absolute excretion; $\mathrm{U}_{\mathrm{Na}} \mathrm{V}^{\circ}=$ Sodium absolute excretion; $C_{c r}=$ creatinine clearance; $(15)_{p}=$ Plasma creatinine Concentration; $[B U N]=$ Blood urea nitrogen; Osmol $_{u}=$ urine osmolarity

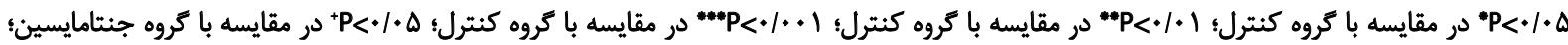

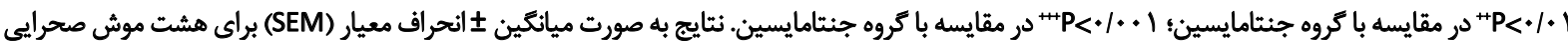


جدول r. تأثير دو روز يس درمان با عصاره اتانولى مرزنجوش بر آسيب باقت كليه موشها

\begin{tabular}{|c|c|c|c|c|c|c|c|c|}
\hline كلومريب كل & فيسوايش & 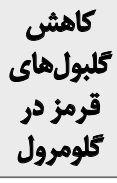 & أسيب كل & شاكوند & ريزش سلولى & تيروتبينينى & نكروز & 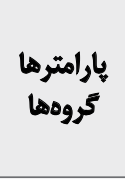 \\
\hline - & . & • & - & - & - & . & - & كتترل \\
\hline ran." & rom & rome. & pano. & remen & remen & reme. & pases & جنتامايسين \\
\hline.$+\cdots$ & ."+ &.+ &.$+\cdots$ &.+ &.$+\cdots$ & ." &.$+\cdots$ & 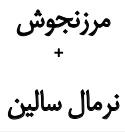 \\
\hline roment+m & 1 & $1000+1+$ & rement+m & rementr & 1 & 1 & remert & 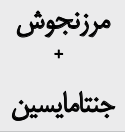 \\
\hline
\end{tabular}

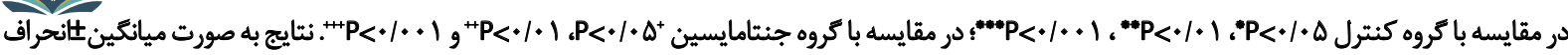

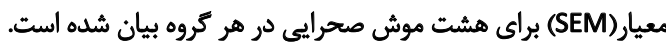

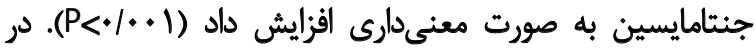

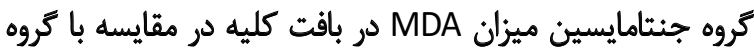

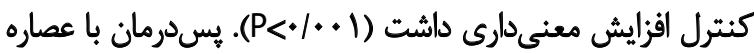

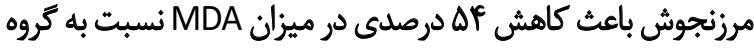

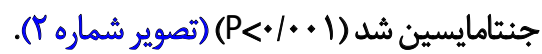

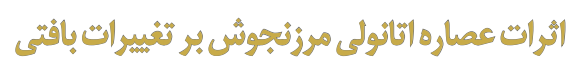

بررسى هاى بافتى نشان داد كه تزريق جنتامايسين (• • ا ميلى مئرم

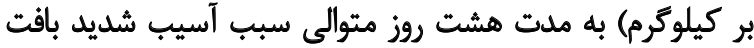

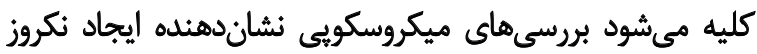

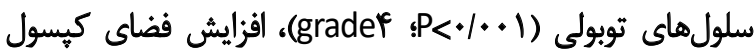

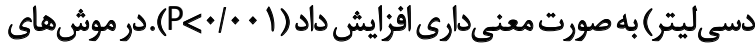

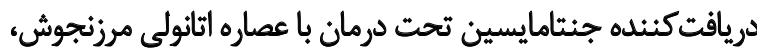

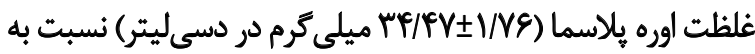

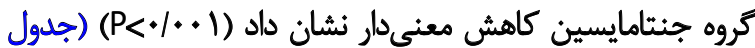

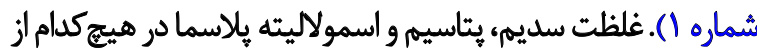
كروهها تغيير معنى ارارى نشان نداد.

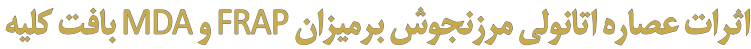

در كروه جنتامايسين ميزان FRAP در بافت كليه در مقايسه با

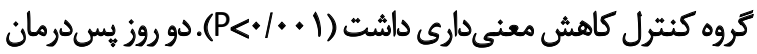

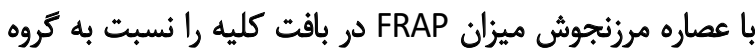
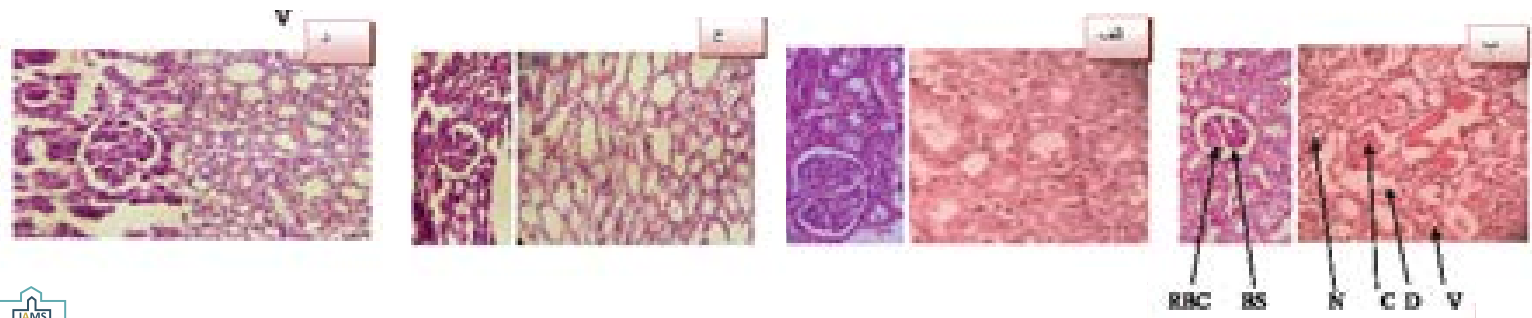

تصوير ז. مقايسه تغييرات هيستولوزيك كليه بين كروهاي مختلف ناشى از هشت روز تجويز جنتامايسين و دو روز هي درمان با عصاره اتانولى مرزنجوش

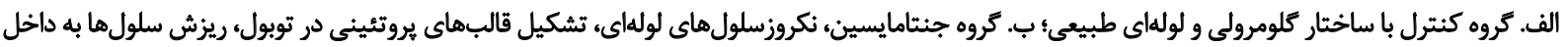

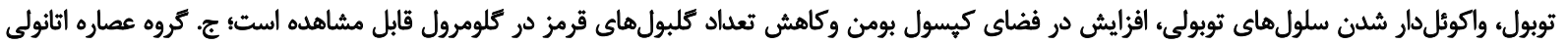

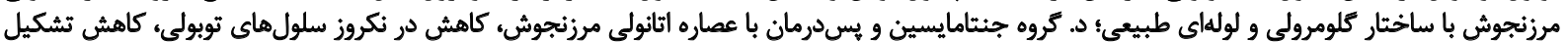

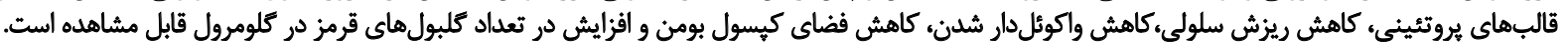
RBC= Red Blood Cells; BS= Bowman's Space; N= Necrosis; C= intratubular Cast; D= Downfall $\mathrm{V}=$ Vacuolization 
در اين تحقيق شبيه مطالعات كذشته جنتامايسين با افزايش

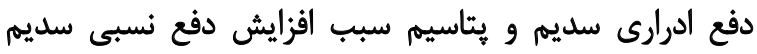

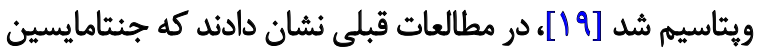

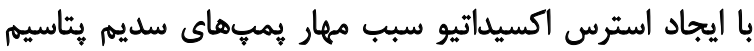

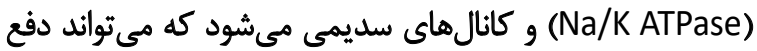

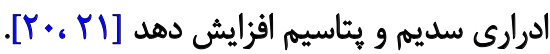

جنتامايسين با توليد ROS سبب انقباض سلولهاى مزائريال

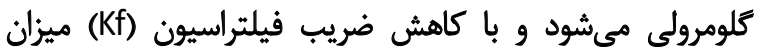

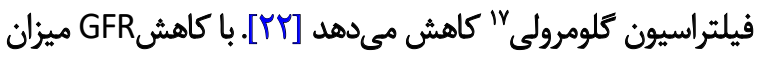

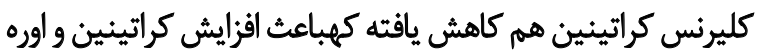

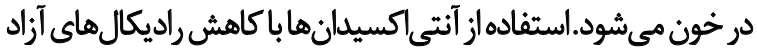

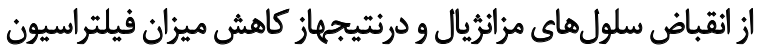

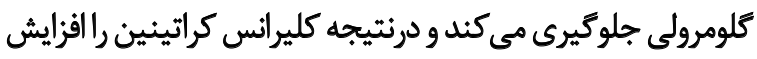

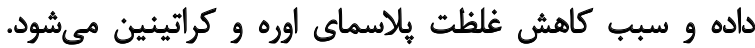

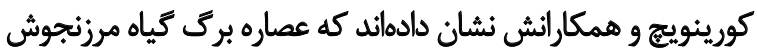

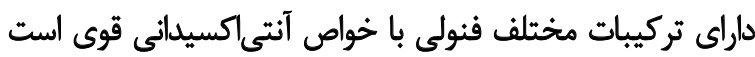

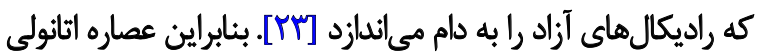

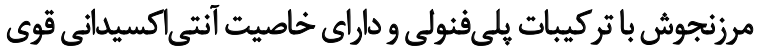

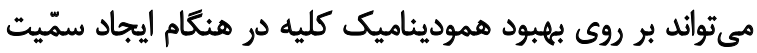

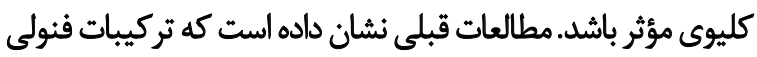

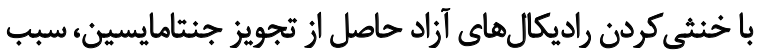

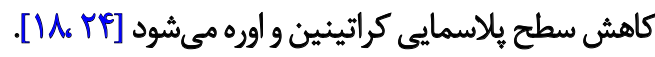

كصاره مرزنجوش به دليل داشتن تركيبات فنولى مي تواند باديا

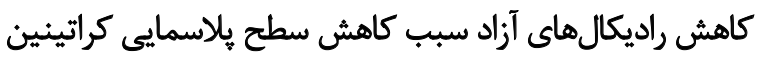

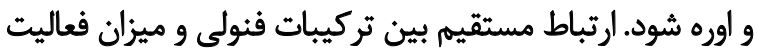

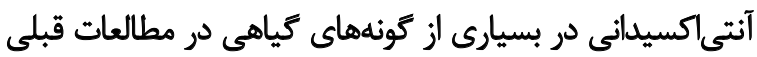

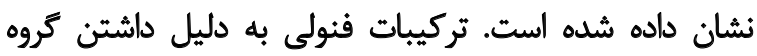

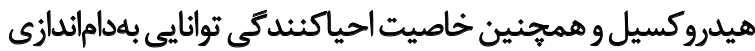

راديكال هاى آزاد را دارند [ـهـ].

يسدرمان با عصاره اتانولى مرزنجوش سبب افزايش كليرنس

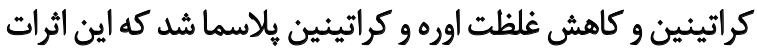

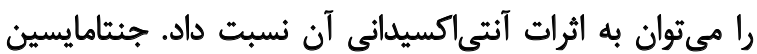

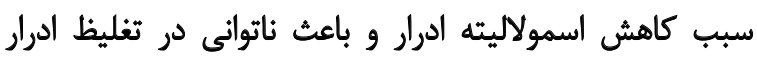

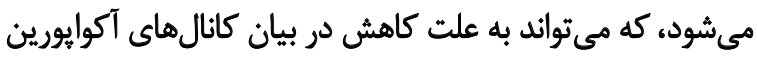

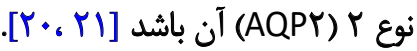

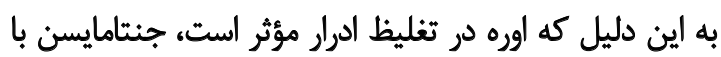

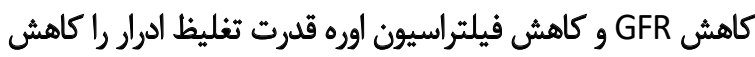

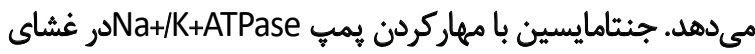

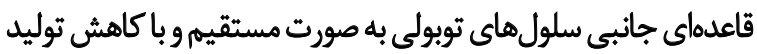

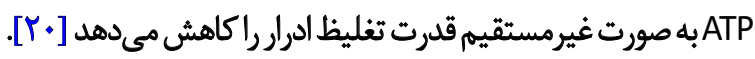
يمبٍ الكترورثيك سديميتاسيم سبب خروج يونهائ سديم ميىشودو

17. Glomerular Filtration Rate (GFR)

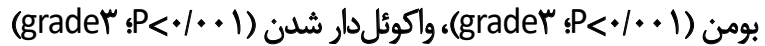

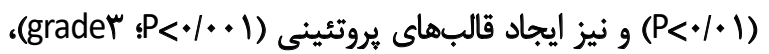

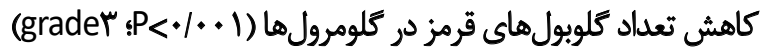

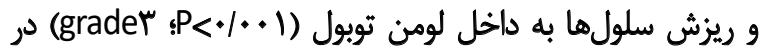

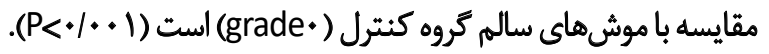

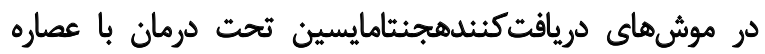

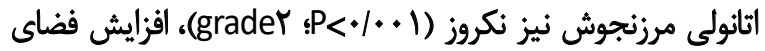

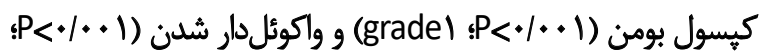

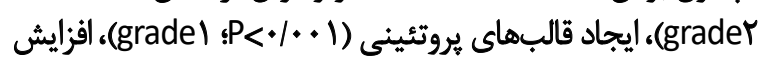

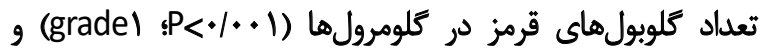

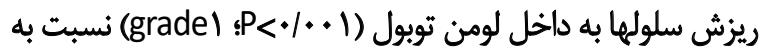

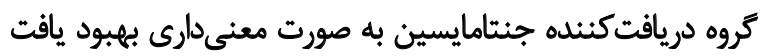

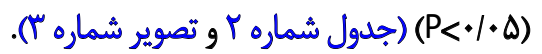

بـ

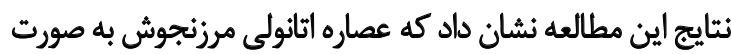

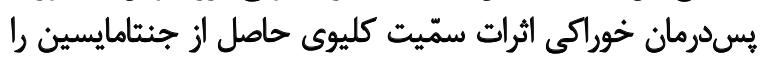

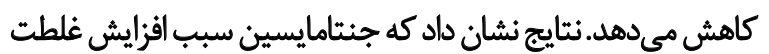

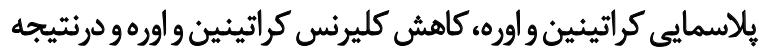

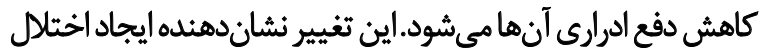

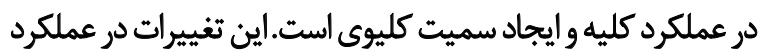

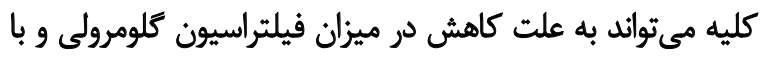

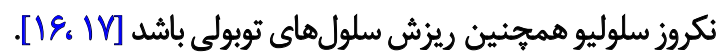
شبيه مطالعات قبلى، جنتامايسين سبب ايجاد نكروز سلولهاي

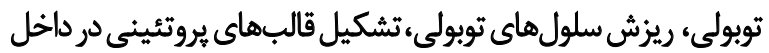

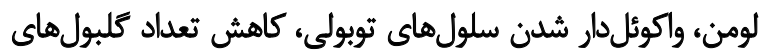

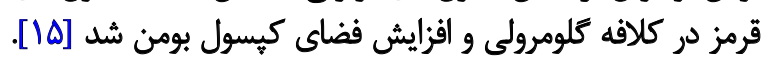

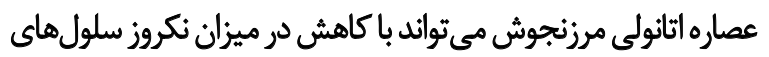

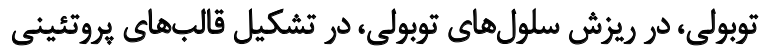

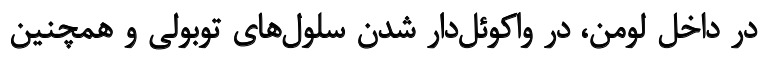

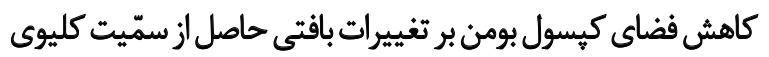
جنتامايسين تأثير داشته باشد [1] ]ـ در اين تحقيق جنتامايسين سبب كاهش معنى دار كليرانس

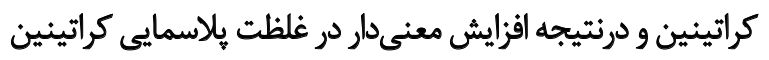

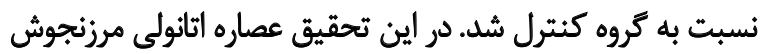

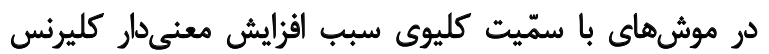

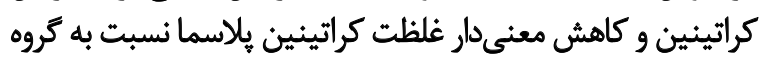
جنتامايسينشد.

جنتامايسين با توليد ROS سبب ايجاد استرس اكسيداتيو در بلن

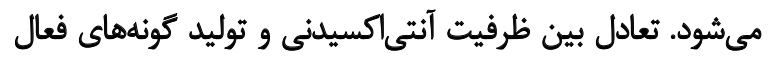

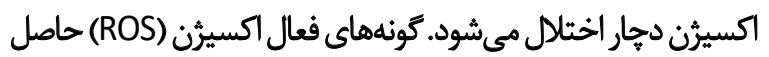

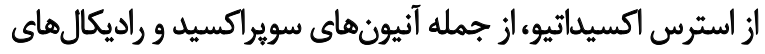

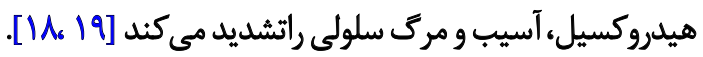


مرزنجوش، تجويز عصاره به دليل بهدامانداختن راديكالهاى آزاد و

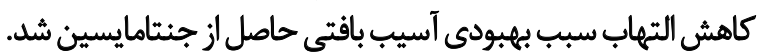

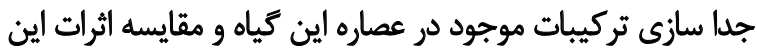

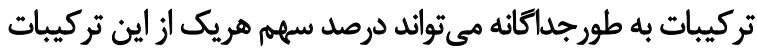

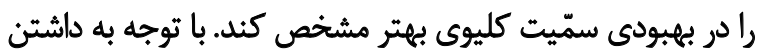

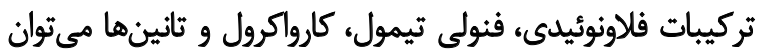

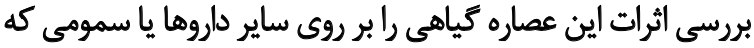
باعث ايجاد سميت كليوى مىشوند يُشئهاد كرد.

\section{نتيجهُكيرى}

نتايج اين مطالعه، نشان داد يسدرمان با عصاره اتانولى مرزنجوش

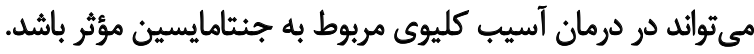

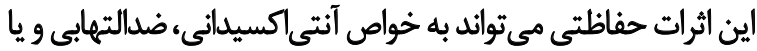

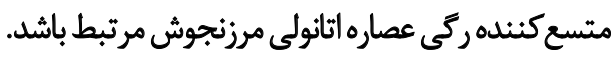

\section{ملاحظات إخلاقى}

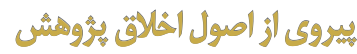

اين مطالعه با كد اخلاق 1-9.1- -9 به به تصويب كميته اخلاق

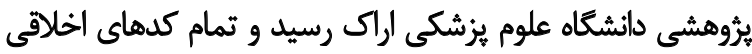

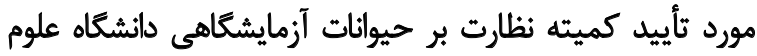

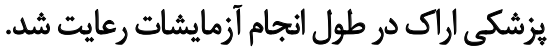

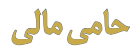

نتايج اين تحقيق حاصل طرح تحقيقاتى مصوب كميته تحقيقات

$$
\text { دانشجويى است. }
$$

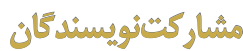

هفهومسازى و روششناسي اعتبارسنجى تحليل دادها: دكثر

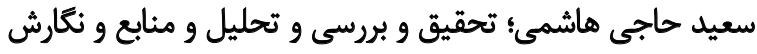
يبشنويس:خانم راضيه رجبى و و عاطفه غياثآبادى.

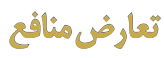

نويسندكان اعلام مي كنيد كه هيجكونه تضاد منافعى در خصوص

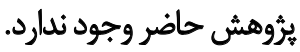

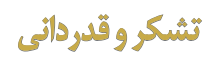

نويسندكان از معاونت محترم تحقيقات و فناورى اطلاعات

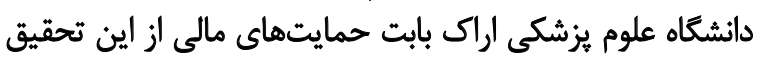

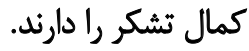

در تنظيم حجم سلول دخالت دارد و مهار اين يمبي سبب ايجاد تورم

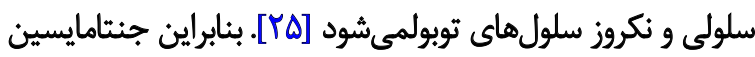

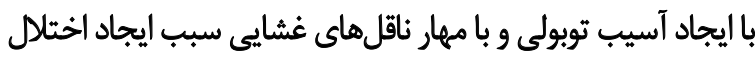

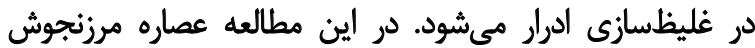

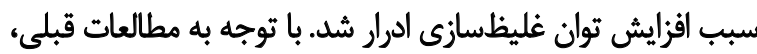

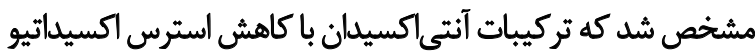

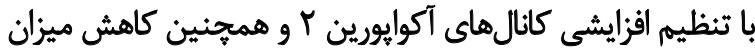

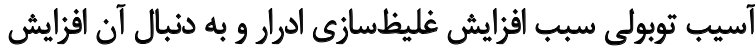

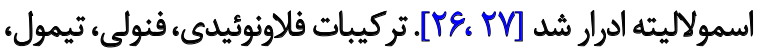

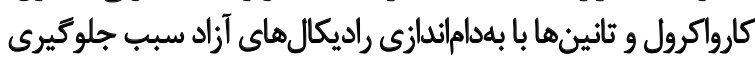

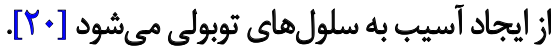
عصاره اتانولى مرزنجوش حاوى فلاونوئيدهاست.فلاونوئيدها داراى

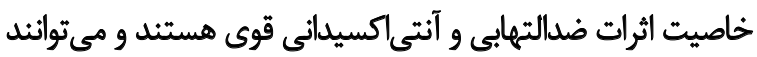

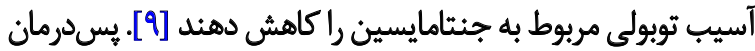

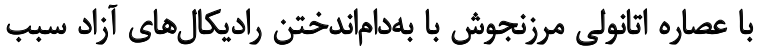

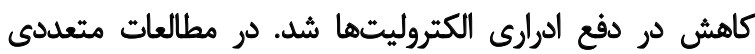

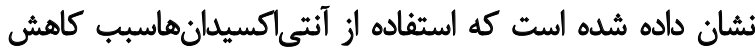

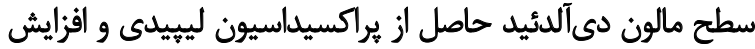

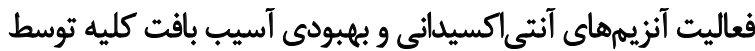

جنتامايسين مىشود [9].].

مطالعات نشان داده است كه عصاره اتانولى مرزنجوش ميثتواند آندي

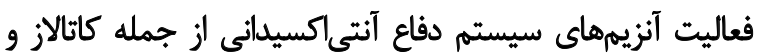

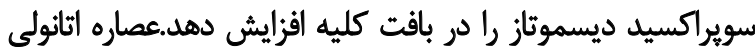

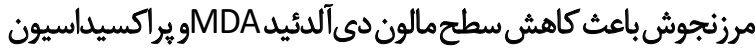

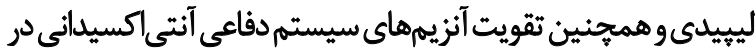

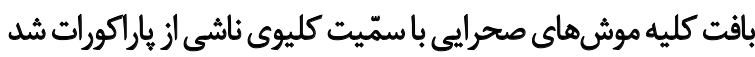

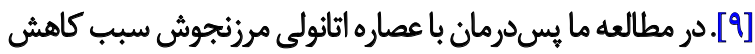

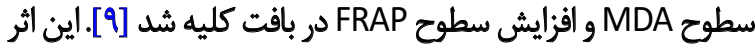
حفاظتى به خواص آنتى اكسيدانى اين كياه مرتبط است.

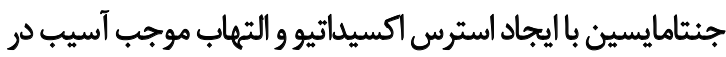

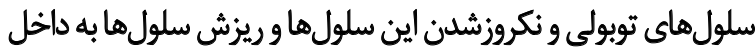

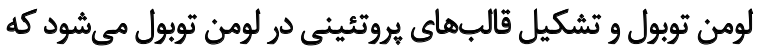

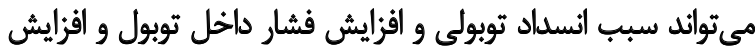

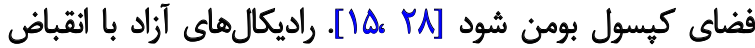

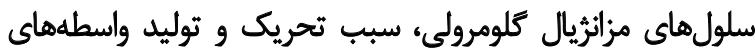

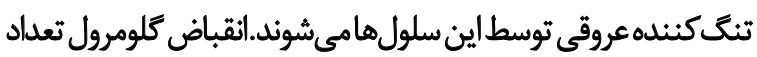

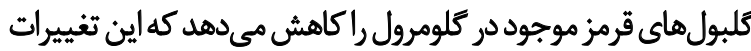

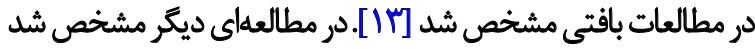

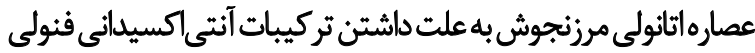

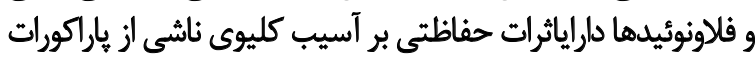

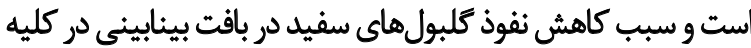

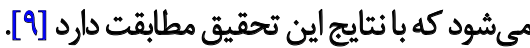
با توجه به اثرات ضدالتهابى و آنتىاكسيدانى عصاره اتانولى 


\section{References}

[1] Pazhayattil GS, Shirali AC. Drug-induced impairment of renal function. Int J Nephrol Renovasc Dis. 2014; 7:457-68. [DOI:10.2147/IJNRD. S39747] [PMID] [PMCID]

[2] Ali BH, Al Za'abi M, Blunden G, Nemmar A. Experimental gentamicin nephrotoxicity and agents that modify it: A mini-review of recent research. Basic Clin Pharmacol Toxicol. 2011; 109(4):225-32. [DOI:10.1111/j.17427843.2011.00728.x] [PMID]

[3] Randjelovic P, Veljkovic S, Stojiljkovic N, Jankovic-Velickovic L, Sokolovic D, Stoiljkovic M, et al. Salicylic acid attenuates gentamicininduced nephrotoxicity in rats. Sci World J. 2012; 2012:390613. [DOI:10.1100/2012/390613] [PMID] [PMCID]

[4] Martinez-Salgado C, Lopez-Hernandez FJ, Lopez-Novoa JM. Glomerular nephrotoxicity of aminoglycosides. Toxicol Appl Pharmacol. 2007; 223(1):86-98. [DOI:10.1016/j.taap.2007.05.004] [PMID]

[5] Randjelovic P, Veljkovic S, Stojiljkovic N, Sokolovic D, Ilic I. Gentamicin nephrotoxicity in animals: Current knowledge and future perspectives. EXCLI J. 2017; 16:388-99.

[6] Morshedloo M, Morshedloo M, Pirali Hamedani M, Yazdani D. An over review to Origanum vulgare $L$. and its pharmacological properties. J Med Plants. 2018; 4(68):15-31.

[7] Oniga I, Pușcaș C, Silaghi-Dumitrescu R, Olah N-K, Sevastre B, Marica $\mathrm{R}$, et al. Origanum vulgare ssp. vulgare: Chemical composition and biological studies. Molecules. 2018; 23(8):1-14. [DOI:10.3390/molecules23082077] [PMID] [PMCID]

[8] Mirzaee A, JaberiHafashani $\mathrm{H}$, Madani A. [Antioxidant activities, total phenols and total Flavonoids assay of Origanurm vulgare, Teucrium polium and Thymus daensis (Persian)]. Hormozgan Med J. 2012; 15(4):285-94.

[9] Sharifi-Rigi A, Heidarian E. Therapeutic potential of Origanum vulgare leaf hydroethanolic extract against renal oxidative stress and nephrotoxicity induced by paraquat in rats. Avicenna J Phytomed. 2019; 9(6):563-73.

[10] Foroozandeh M, Bigdeli M, Rahnema M. [The effect of hydroalcoholic extract of Origanum vulgare on Blood Brain Barrier (BBB) permeability and neurologic deficits in rat stroke model (Persian)]. J Torbat Heydariyeh Univ Med Sci. 2014; 2(3):1-9.

[11] Srihari T, Sengottuvelan M, Nalini N. Dose-dependent effect of oregano (Origanum vulgare L.) on lipid peroxidation and antioxidant status in 1, 2-dimethylhydrazine-induced rat colon carcinogenesis. J Pharm Pharmacol. 2008; 60(6):787-94. [DOI:10.1211/jpp.60.6.0015] [PMID]

[12] Bankova R. Oleum oregano-properties and application. Tradit Modern Veterin Med. 2017; 2(1):25-30.

[13] Hajihashemi S, Hamidizad Z, Rahbari A, Ghanbari F, Motealeghi ZA. Effects of cobalamin (Vitamin $B_{12}$ ) on gentamicin induced nephrotoxicity in rat. Drug Res. 2017; 67(12):710-8. [DOI:10.1055/s-0043-117418] [PMID]

[14] Ahmadi F, Hajihashemi S, Rahbari A, Ghanbari F. Effects of nitroglycerine on renal ischemia-reperfusion injury in adult male rats. Drug Res. 2019; 69(11):612-20. [DOI:10.1055/a-0958-1987] [PMID]

[15] Hajihashemi S, Jafarian T, Ahmadi M, Rahbari A, Ghanbari F. Ameliorative effects of zataria multiflora hydro-alcoholic extract on gentamicin induced nephrotoxicity in rats. Drug Res. 2018; 68(07):387-94. [DOI:10.1055/s-0043-124968] [PMID]
[16] Cuzzocrea S, Thiemermann C, Salvemini D. Potential therapeutic effect of antioxidant therapy in shock and inflammation. Current Med Chemist. 2004; 11(9):1147-62. [DOI:10.2174/0929867043365396] [PMID]

[17] Savin V, Karniski L, Cuppage F, Hodges G, Chonko A. Effect of gentamicin on isolated glomeruli and proximal tubules of the rabbit. Lab Invest. 1985; 52(1):93-102.

[18] Aydin G, Gökçimen A, Öncü M, Çicek E, Karahan N, Gökalp O. Histopathologic changes in liver and renal tissues induced by different doses of diclofenac sodium in rats. Turkish J Vet Anim Sci. 2003; 27(5):1131-40.

[19] Karahan I, Ateşşahin A, Yılmaz S, Çeribaşı A, Sakin F. Protective effect of lycopene on gentamicin-induced oxidative stress and nephrotoxicity in rats. Toxicology. 2005; 215(3):198-204. [DOI:10.1016/j. tox.2005.07.007] [PMID]

[20] Gowrisri M, Kotagiri S, Vrushabendra Swamy B, Archana Swamy $P$ Vishwanath K. Anti-oxidant and nephroprotective activities of Cassia occidentalis leaf extract against gentamicin induced nephrotoxicity in rats. Res J Pharm Biol Chem Sci. 2012; 3:684-94.

[21] Bae WK, Lee J, Park JW, Bae EH, Ma SK, Kim SH, et al. Decreased expression of $\mathrm{Na}^{+} / \mathrm{K}^{+}$-ATPase, NHE3, NBC1, AQP1 and OAT in gentamicininduced nephropathy. The Korean J Physiol Pharmacol. 2008; 12(6):331 6. [DOI:10.4196/kjpp.2008.12.6.331] [PMID] [PMCID]

[22] Martínez-Salgado C, Eleno N, Tavares P, Rodríguez-Barbero A, GarcíaCriado J, Bolaños JP, et al. Involvement of reactive oxygen species on gentamicin-induced mesangial cell activation. Kidney Int. 2002 62(5):1682-92. [DOI:10.1046/j.1523-1755.2002.00635.x] [PMID]

[23] Kaurinovic B, Popovic M, Vlaisavljevic S, Trivic S. Antioxidant capacity of Ocimum basilicum L. and Origanum vulgare L. extracts. Molecules. 2011; 16(9):7401-14. [DOI:10.3390/molecules16097401] [PMID] [PMCID]

[24] Ali Nam, Saeed SZ. Nephro-protective effect of Punica granatum in gentamicin-induced nephrotoxicity in rats. Med J Babylon. 2012 9(1):220-8.

[25] Kaledaite R, Bernatoniene J, Majiene D, Dvorackova K, Masteikova R, Muselik J, et al. Investigation of antiradical activity of Salvia officinalis L., Urtica dioica L., and Thymus vulgaris L. extracts as potential candidates for a complex therapeutic preparation. J Med Plants Res. 2011 5(25):6090-6.

[26] Williams P, Trimble M, Crespo L, Holohan P, Freedman J, Ross C. Inhibition of renal $\mathrm{Na}^{+}, \mathrm{K}^{+}$-adenosine triphosphatase by gentamicin. J Pharmacol Exp Ther. 1984; 231(2):248-53.

[27] Sohn EJ, Kang DG, Lee HS. Protective effects of glycyrrhizin on gentamicin-induced acute renal failure in rats. Pharmacol Toxicol. 2003; 93(3):116-22. [DOI:10.1034/j.1600-0773.2003.930302.x] [PMID]

[28] Neugarten J, Aynedjian HS, Bank N. Role of tubular obstruction in acute renal failure due to gentamicin. Kidney Int. 1983; 24(3):330-5. [DOI:10.1038/ki.1983.162] [PMID] 